\title{
The impact of the location of a chronic total occlusion in a non-infarct-related artery on long-term mortality in ST-elevation myocardial infarction patients
}

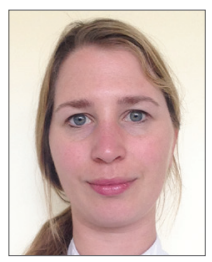

Loes P.C. Hoebers, MD; Joëlle Elias, MD; Ivo M. van Dongen, MD;

Dagmar M. Ouweneel, MSc; Bimmer E.P.M. Claessen, MD, PhD; Jan J. Piek, MD, PhD; Jose P.S. Henriques*, MD, PhD

AMC Heart Center, Academic Medical Center, University of Amsterdam, Amsterdam, The Netherlands

L.P.C. Hoebers and J. Elias contributed equally to this manuscript.

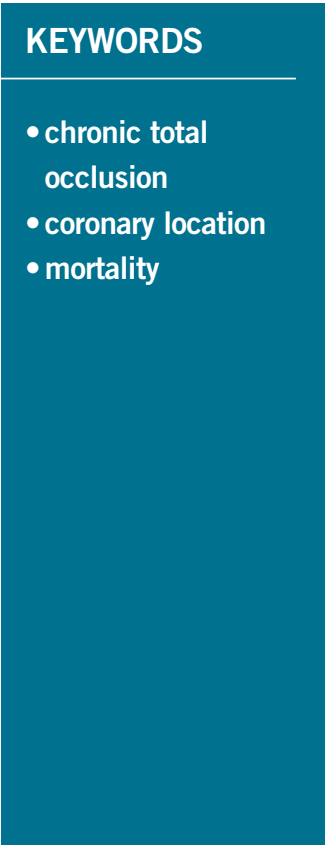

\section{Abstract}

Aims: Several studies have evaluated the impact of a CTO on short- and long-term mortality in STEMI patients. It has been speculated that the adverse effect on prognosis could differ per coronary location. The purpose of this study was to evaluate whether the long-term prognosis of STEMI patients differs according to the coronary location of the CTO.

Methods and results: Between 2000 and 2012, a total of 480 STEMI patients with a CTO in a noninfarct-related artery were included. The primary outcome for the present analysis was three-year allcause mortality, evaluating the impact of the coronary CTO and infarct location. Four hundred and thirteen patients had a single CTO in a non-infarct-related artery, whereas 67 patients had more than one CTO and in this group mortality was higher. In patients with a single CTO, the highest risk of mortality was observed when the culprit lesion was located in the LAD or proximal LCX or when the CTO lesion was located in the proximal LAD.

Conclusions: We previously reported that STEMI patients with a CTO have a worse prognosis than STEMI patients without a CTO. We now show that, in these patients, LAD or proximal LCX location for the culprit lesion, or proximal LAD location for the CTO lesion, is associated with the highest risk. As a result, almost all CTO patients are at increased risk for mortality due to the combination of the culprit and CTO artery location.

*Corresponding author: Department of Cardiology, Academic Medical Center - University of Amsterdam, Meibergdreef 9, 1105 AZ Amsterdam, The Netherlands.E-mail:j.p.henriques@amc.uva.nl 


\section{Introduction}

Increased angiographic severity and the extent of coronary artery disease are associated with higher mortality ${ }^{1-4}$. Coronary chronic total occlusions (CTO) are often considered the most complex expression of coronary artery disease (CAD). In patients with significant coronary artery disease a CTO is present in approximately $16 \% \%^{5,6}$. Previously, several studies in patients with stable coronary artery disease have reported that successful versus failed elective CTO revascularisation has been associated with symptom relief", reduced need for coronary artery bypass surgery ${ }^{8}$, improvement of electrical stability ${ }^{9,10}$ and left ventricular function and even reduced mortality. A recent meta-analysis reported an increment of $4.44 \%$ in left ventricular ejection fraction and reduced long-term mortality after successful versus failed CTO revascularisation (OR: 0.52) ${ }^{11}$. However, it has been postulated that these beneficial effects might vary according to the anatomical location of the CTO, showing only an improved survival after treatment of the left anterior descending coronary artery (LAD) and left circumflex (LCX) but not the right coronary artery (RCA) $)^{12,13}$.

Several studies have shown a strong association between the presence of a concurrent CTO in ST-elevation myocardial infarction (STEMI) patients and short- and long-term mortality ${ }^{14-17}$. The purpose of this study was to evaluate whether the long-term prognosis of STEMI patients differs according to the coronary location of the CTO.

\section{Methods \\ STUDY COHORT}

From January 2000 to December 2012, STEMI patients with a CTO in a non-infarct-related artery (IRA) treated with primary percutaneous coronary intervention (PCI) in our hospital, for whom the diagnostic angiography was available, were entered into a dedicated database after informed consent was obtained and approval by our institutional review committee granted. Acute STEMI was diagnosed when patients had symptoms of an acute myocardial infarction lasting 30 minutes to 12 hours, accompanied by an electrocardiogram with ST-segment elevation $>1 \mathrm{~mm}(0.1 \mathrm{mV})$ in $\geq 2$ contiguous leads. Patients were immediately transported to the cardiac catheterisation laboratory and underwent coronary angiography with a view to performing primary PCI. PCI was performed using standard techniques, provided the coronary anatomy was suitable.

Prior to PCI, all patients were treated with heparin $(5,000 \mathrm{IU})$ and aspirin $(500 \mathrm{mg})$. Adjunctive treatment with glycoprotein $\mathrm{IIb} /$ IIIa inhibitors was at the discretion of the operator. Post-PCI antiplatelet therapy was prescribed according to the guidelines: clopidogrel, prasugrel or ticagrelor. Duplicate patients due to recurrent STEMI or patients lost to follow-up were excluded. Patients with previous CABG surgery were excluded due to the complexity of interarterial connections and patency of the graft and native vessel.

\section{DATA COLLECTION}

Baseline characteristics were collected prospectively in the aforementioned dedicated database. Information on vital status was obtained from the Dutch national population register (Statistics Netherlands, Voorburg, The Netherlands). Patient data were checked for inconsistency and completeness.

\section{ANGIOGRAPHIC ANALYSIS}

All coronary angiograms were reviewed by an experienced CTO operator (J. Henriques) and an interventional research fellow (L. Hoebers).

\section{DEFINITIONS}

A CTO was defined as a $100 \%$ luminal narrowing in a non-IRA before PCI without antegrade flow or with antegrade or retrograde filling through collateral vessels. Proximal lesions were considered segment 6 or 7 for the LAD coronary artery and segment 11 for the LCX coronary artery.

\section{PRIMARY OUTCOME}

The primary outcome for the present analysis was three-year allcause mortality in STEMI patients with a CTO, evaluating the impact of the coronary CTO location corrected for the location of the culprit artery, with the exclusion of left main lesions and multiple CTO patients due to their low prevalence.

\section{STATISTICAL ANALYSIS}

Discrete variables were summarised as frequencies and percentages. Differences in baseline characteristics between the groups were tested for significance by the $\chi^{2}$ test. Statistical significance was defined as a p-value $<0.05$. Cumulative event rates of allcause death were estimated using the Kaplan-Meier method and compared using the log-rank statistic. Follow-up for mortality was censored at the date of last follow-up by checking vital status in the Dutch population register, or at three years, whichever came first. Hazard ratios for all-cause mortality were calculated using Cox proportional hazards regression analyses after verification of the proportional hazards assumption. The multivariable model was built by adding covariates from the baseline characteristics table with a p-value $<0.10$ in univariate analysis. All variables with a p-value $>0.10$ were removed from the model.

\section{Results}

Between 2000 and 2012, 6,771 unique STEMI patients underwent primary PCI in our hospital, of whom 744 (11\%) had a CTO (Figure 1). In 172 (23\%) CTO patients the coronary angiogram was irretrievable and in seven (1\%) patients the quality of the angiogram was insufficient for analysis. Of the remaining patients, $72(10 \%)$ were excluded due to previous CABG and $13(2 \%)$ patients did not receive primary PCI, resulting in a CTO cohort of 480 patients.

\section{PATIENT CHARACTERISTICS}

Of these 480 patients, 413 had a single CTO in a non-IRA whereas 67 patients had more than one CTO (Table 1). The majority of the CTO patients were male $(76 \%)$ with a mean age of 64 years (55-74). Approximately one quarter of the patients had a previous 
Table 1. Baseline characteristics of STEMI patients with a CTO, overall and stratified for the coronary location.

\begin{tabular}{|c|c|c|c|c|c|c|c|}
\hline \multicolumn{2}{|c|}{ 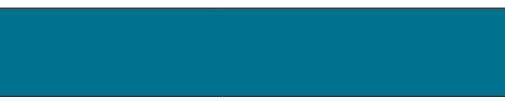 } & $\begin{array}{l}\text { All patients } \\
\quad(n=480)\end{array}$ & $\begin{array}{c}\text { Single CTO RCA } \\
\qquad(n=196)\end{array}$ & $\begin{array}{l}\text { Single CTO LAD } \\
\qquad(n=93)\end{array}$ & $\begin{array}{l}\text { Single CTO LCX } \\
\qquad(n=124)\end{array}$ & $p$-value* & $\begin{array}{c}\text { Multiple CTO } \\
\quad(n=67)\end{array}$ \\
\hline \multicolumn{2}{|c|}{ Male gender (\%) } & 75.8 & 75.5 & 74.2 & 72.6 & 0.84 & 85.1 \\
\hline \multicolumn{2}{|c|}{ Age, median (IQR) } & $64.3(55-74)$ & 63.5 (53.3-72.8) & $65(54-76)$ & $66(56-73.8)$ & 0.22 & $65.8(53-68.7)$ \\
\hline \multicolumn{2}{|l|}{ Diabetes (\%) } & 16.0 & 19.5 & 11.2 & 16.4 & 0.23 & 15.2 \\
\hline \multicolumn{2}{|c|}{ Hypertension (\%) } & 3.8 & 36.3 & 32.6 & 38.5 & 0.67 & 33.3 \\
\hline \multicolumn{2}{|c|}{ Hyperlipidaemia (\%) } & 32.5 & 34.0 & 25.0 & 36.7 & 0.19 & 30.3 \\
\hline \multicolumn{2}{|c|}{ Current smoker (\%) } & 44.3 & 46.2 & 40.2 & 41.0 & 0.54 & 49.3 \\
\hline \multicolumn{2}{|c|}{ Previous MI (\%) } & 25.4 & 22.1 & 33.3 & 24.6 & 0.13 & 25.8 \\
\hline \multicolumn{2}{|c|}{ Cardiogenic shock (\%) } & 25.8 & 26.5 & 17.2 & 25 & 0.21 & 37.3 \\
\hline \multirow{3}{*}{$\begin{array}{l}\text { Coronary } \\
\text { anatomy }\end{array}$} & Right dominance (\%) & 88.3 & 85.6 & 92.5 & 89.5 & \multirow{3}{*}{$<0.01$} & 89.6 \\
\hline & Left dominance (\%) & 4.8 & 2.1 & 4.3 & 8.9 & & 6.0 \\
\hline & Balanced (\%) & 6.7 & 12.3 & 3.2 & 1.6 & & 4.5 \\
\hline \multicolumn{2}{|c|}{ Multiple CTOs (\%) } & 14.0 & - & - & - & - & 100 \\
\hline \multicolumn{2}{|c|}{ Three-vessel disease } & 54.8 & 46.1 & 48.4 & 55.6 & 0.25 & 100 \\
\hline \multirow{4}{*}{$\begin{array}{l}\text { Culprit lesion } \\
(\%)\end{array}$} & $\mathrm{RCA}(\%)$ & 32.1 & - & 72 & 58.9 & \multirow{4}{*}{$<0.01$} & 20.9 \\
\hline & LCX (\%) & 23.1 & 36.7 & 28 & - & & 19.4 \\
\hline & LAD (\%) & 43.8 & 61.7 & - & 40.3 & & 58.2 \\
\hline & LM (\%) & 1.0 & 1.5 & - & 0.8 & & 1.5 \\
\hline \multicolumn{2}{|c|}{ Stent placement (\%) } & 90.4 & 88.2 & 92.5 & 93.5 & 0.22 & 89.6 \\
\hline \multicolumn{2}{|c|}{ DES use $(\%)$} & 18.4 & 19.6 & 11.8 & 21.0 & 0.18 & 19.7 \\
\hline \multicolumn{2}{|c|}{ TIMI 3 flow pre PPCI (\%) } & 19.4 & 16.3 & 24.7 & 17.7 & 0.22 & 23.9 \\
\hline \multicolumn{2}{|c|}{ TIMI 3 flow post PPCI (\%) } & 85.0 & 81.6 & 87.1 & 85.5 & 0.43 & 91.0 \\
\hline \multicolumn{2}{|c|}{ Mortality at 3 years } & 25.8 & 28.1 & 22.6 & 21.8 & 0.36 & 31.3 \\
\hline
\end{tabular}

MI and a similar proportion of patients were in cardiogenic shock on presentation. The culprit lesion was in the LAD in $44 \%$ of patients, in the RCA in $32 \%$ of patients, in the LCX in $23 \%$ of patients, and in the left main in $1 \%$. The last group was excluded from the primary analysis due to its low prevalence. The culprit lesion was most often treated with stent placement (90\%), with

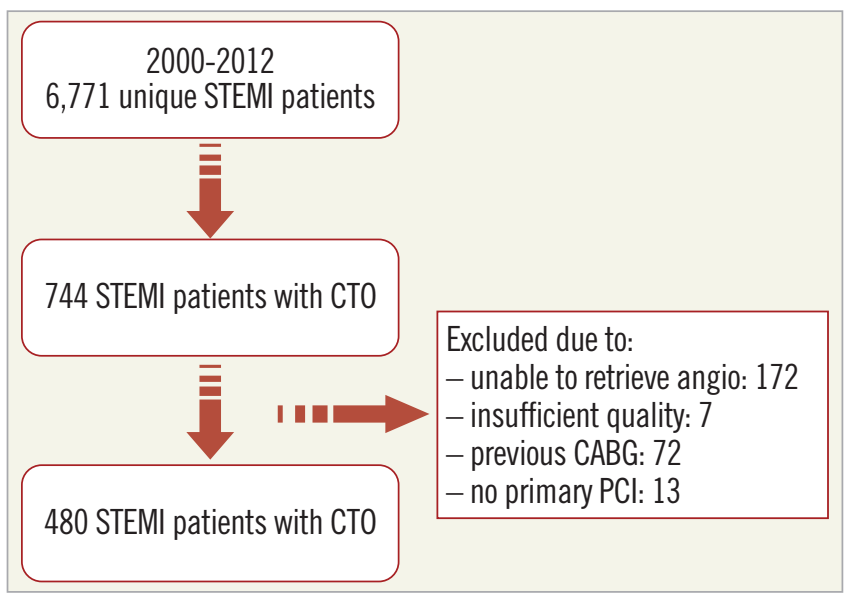

Figure 1. Flow chart. CABG: coronary artery bypass graft surgery; CTO: chronic total occlusion; PCI: percutaneous coronary intervention; STEMI: ST-segment elevation myocardial infarction a post-procedural Thrombolysis In Myocardial Infarction flow grade 3 in $85 \%$. Among patients with a single CTO in a nonIRA, the CTO was most often located in the RCA (47\%) and less often in the LCX (30\%) and LAD (23\%). There were no significant differences regarding the baseline characteristics among these groups.

Figure 2 shows the three-year mortality of the STEMI cohort stratified according to single versus multiple CTO. Long-term mortality was higher in the latter group. Since these patients have an increased risk compared to single CTO patients, they were excluded from the primary analysis.

\section{PROGNOSTIC IMPACT ACCORDING TO CORONARY LOCATION}

Figure 3 shows long-term mortality according to the location of the culprit artery and Figure 4 shows mortality after stratification of the cohort according to the CTO artery. In this cohort the mortality of STEMI patients with a CTO and the culprit artery in the LAD $(31 \%)$ or LCX $(26 \%)$ was comparable, while mortality in the RCA group was lower (16\%). When the cohort was stratified according to the location of the CTO (Figure 4), the highest mortality was observed in STEMI patients with a CTO located in the RCA (28\%), and the lowest mortality in patients with a CTO in the LAD (23\%) or LCX (21\%). When corrected for the location of the culprit artery and other significant variables, a CTO located in 


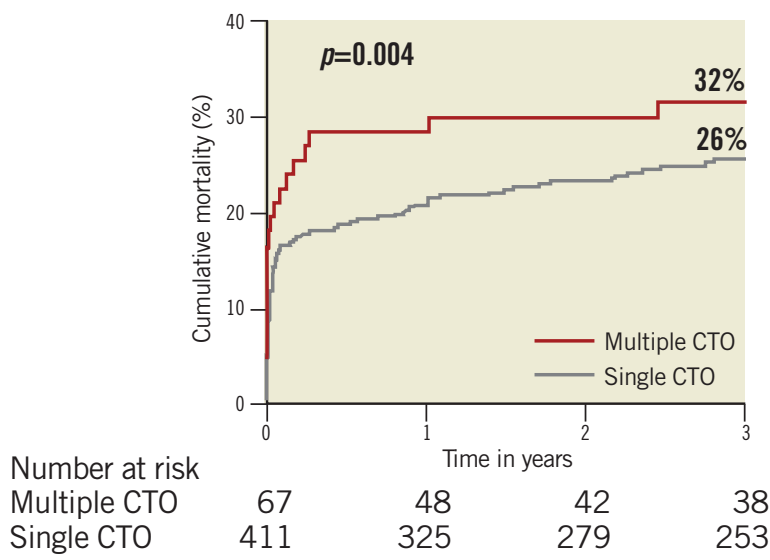

Figure 2. Mortality in STEMI patients with a single versus multiple CTO. CTO: chronic total occlusion; STEMI: ST-segment elevation myocardial infarction

the LAD was associated with a non-significant increased risk for mortality compared to a CTO located in the RCA or LCX (HR: 1.6, 95\% CI: $0.8-3.1, \mathrm{p}=0.15$, HR 1.2, 95\% CI: 0.7-2.0, p=0.60) (Table 2). When the left coronary system was stratified into a proximal and distal part, a CTO located in the proximal LAD was associated with significantly increased mortality compared with a CTO located in the RCA (HR: 2.2, 95\% CI: 1.1-4.5, p=0.02) (Table 2). For the culprit lesion, a location in the LAD or proximal LCX was associated with a worse survival compared to the RCA (Table 2). As a result, when the CTO is located in the RCA, the culprit artery

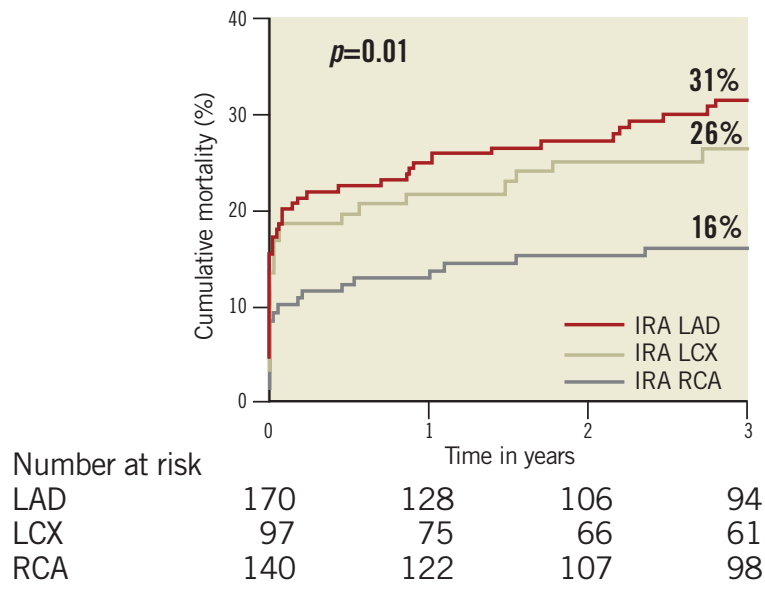

Figure 3. Mortality in STEMI patients with a single CTO stratified according to culprit-related artery. CTO: chronic total occlusion; $L A D$ : left anterior descending artery; $L C X$ : left circumflex artery; $R C A$ : right coronary artery; STEMI: ST-segment elevation myocardial infarction

must be situated in the LAD or LCX and thus, through the combination of CTO and the location, the majority of the cohort was at a high risk for mortality (Table 3 ). Patients with the culprit artery in the RCA and a concurrent CTO in the LAD or LCX had the lowest absolute three-year mortality rate. In all other combinations, the mortality rate was at least twice as high, with the highest mortality rate in patients with a culprit artery located in the LCX

Table 2. The predictive value of coronary lesion location, including proximal or distal location, for long-term mortality (cardiogenic shock not included in the model).

\begin{tabular}{|c|c|c|c|c|c|c|c|}
\hline & HR & $95 \% \mathrm{CI}$ & $p$-value & HR & $95 \% \mathrm{CI}$ & $\boldsymbol{p}$-value \\
\hline & & \multicolumn{3}{|c|}{ Univariate analysis } & \multicolumn{3}{|c|}{ Multivariate correction } \\
\hline \multirow[t]{3}{*}{ Infarct-related artery } & RCA & - & - & - & - & & \\
\hline & LAD & 2.1 & $1.3-3.5$ & 0.02 & 2.7 & $1.4-5.2$ & $<0.01$ \\
\hline & LCX & 1.7 & $1.0-3.1$ & 0.06 & 2.3 & $1.2-4.5$ & 0.01 \\
\hline \multirow[t]{3}{*}{ CTO-related artery } & RCA & - & - & - & - & & \\
\hline & LAD & 0.8 & $0.5-1.3$ & 0.49 & 1.6 & $0.8-3.1$ & 0.15 \\
\hline & LCX & 0.8 & $0.5-1.2$ & 0.48 & 1.2 & $0.7-2.0$ & 0.60 \\
\hline
\end{tabular}

Proximal/distal lesion location

\begin{tabular}{|c|c|c|c|c|c|c|c|}
\hline \multirow[t]{5}{*}{ Infarct-related artery } & $\mathrm{RCA}$ & - & - & - & - & & \\
\hline & LAD proximal & 2.0 & $1.2-3.4$ & $<0.01$ & 2.6 & $1.3-5.0$ & $<0.01$ \\
\hline & LAD distal & 2.6 & $1.3-5.4$ & $<0.01$ & 2.9 & $1.1-7.2$ & 0.02 \\
\hline & LCX proximal & 1.9 & $0.9-3.8$ & 0.08 & 2.4 & $1.1-5.6$ & 0.04 \\
\hline & LCX distal & 1.6 & $0.8-3.2$ & 0.18 & 1.9 & $0.9-3.9$ & 0.10 \\
\hline \multirow[t]{5}{*}{ СTO-related artery } & $\mathrm{RCA}$ & - & - & - & - & & \\
\hline & LAD proximal & 1.2 & $0.7-2.0$ & 0.51 & 2.2 & $1.1-4.5$ & 0.02 \\
\hline & LAD distal & 0.2 & $0.05-0.8$ & 0.03 & 0.5 & $0.1-2.1$ & 0.32 \\
\hline & LCX proximal & 0.6 & $0.3-1.4$ & 0.25 & 0.7 & $0.3-1.8$ & 0.48 \\
\hline & LCX distal & 0.8 & $0.5-1.4$ & 0.48 & 1.4 & $0.8-2.5$ & 0.28 \\
\hline
\end{tabular}

Multivariate analysis: corrected for age, gender and statin use. Cl: confidence interval; CTO: chronic total occlusion; HR: hazard ratio; LAD: left anterior descending artery; LCX: left circumflex coronary artery; RCA: right coronary artery; STEMI: ST-elevation myocardial infarction 


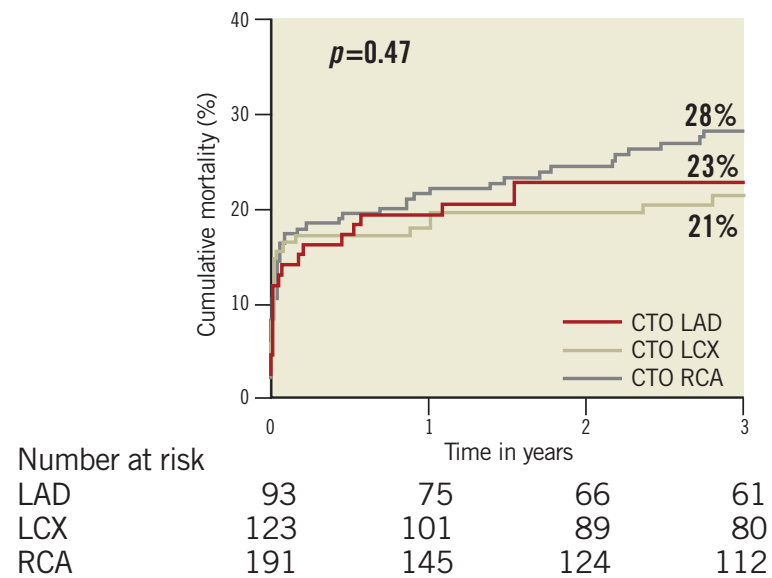

Figure 4. Mortality in STEMI patients with a single CTO stratified according to CTO-related artery. CTO: chronic total occlusion; $L A D$ : left anterior descending artery; LCX: left circumflex artery; $R C A$ : right coronary artery; STEMI: ST-segment elevation myocardial infarction

Table 3. Three-year absolute mortality in STEMI patients with a single CTO in a non-IRA.

\begin{tabular}{|l|c|c|c|}
\hline & IRA-RCA & IRA-LAD & IRA-LCX \\
\hline CTO-RCA & - & $30.6 \%$ & $20.8 \%$ \\
\hline CTO-LAD & $16.4 \%$ & - & $38.5 \%$ \\
\hline CTO-LCX & $15.1 \%$ & $30.0 \%$ & - \\
\hline
\end{tabular}

and the CTO artery located in the LAD. When cardiogenic shock was included in the model, only age remained a significant predictor for mortality (Table 4).

\section{Discussion}

Previous literature has shown increased mortality in STEMI patients with versus without a CTO in a non-IRA. In this paper, we showed that in these patients the highest mortality was observed when a CTO was located in the proximal LAD or the culprit artery in the LAD or proximal LCX. Until now, there have been no reports in the literature in which mortality has been evaluated in STEMI patients with a CTO in a non-IRA according to the coronary location of the CTO and the culprit artery, although the importance of the LAD seems intuitive, as reduced mortality might be explained by the prognostic significance of left ventricular function. As left ventricular function is related to cardiogenic shock, it could explain our finding that all prognostic significance of CTO or culprit location was lost after adding cardiogenic shock into the multivariate model. The importance of the anterior wall of the left ventricle on prognosis, which is for the most part dependent on the LAD for blood supply, has been well documented both in stable coronary artery disease and in patients with myocardial infarction ${ }^{18-20}$. Compared with a myocardial infarction not related to the LAD, or distal versus proximal LAD-related myocardial infarction, those patients have a worse clinical outcome in terms of mortality, haemodynamic instability, and need for left ventricular assist devices, which is probably due to lower residual

Table 4. The predictive value of coronary lesion location, including proximal or distal location, for long-term mortality (cardiogenic shock included in the model).

\begin{tabular}{|c|c|c|c|c|c|c|c|}
\hline & HR & $95 \%$ CI & $p$-value & HR & $95 \%$ CI & $\boldsymbol{p}$-value \\
\hline & & \multicolumn{3}{|c|}{ Univariate analysis } & \multicolumn{3}{|c|}{ Multivariate correction } \\
\hline \multirow[t]{3}{*}{ Infarct-related artery } & $\mathrm{RCA}$ & - & - & - & - & & \\
\hline & LAD & 2.1 & $1.3-3.5$ & 0.02 & 1.2 & $0.6-2.4$ & 0.59 \\
\hline & LCX & 1.7 & $1.0-3.1$ & 0.06 & 1.2 & $0.6-2.3$ & 0.69 \\
\hline \multirow[t]{3}{*}{ CTO-related artery } & $\mathrm{RCA}$ & - & - & - & - & & \\
\hline & LAD & 0.8 & $0.5-1.3$ & 0.49 & 1.2 & $0.6-2.3$ & 0.60 \\
\hline & LCX & 0.8 & $0.5-1.2$ & 0.48 & 0.9 & $0.5-1.5$ & 0.57 \\
\hline
\end{tabular}

Proximal/distal lesion location*

\begin{tabular}{|l|l|c|c|c|c|c|c|}
\hline Infarct-related artery & RCA & - & - & - & - & \\
\cline { 2 - 7 } & LAD proximal & 2.0 & $1.2-3.4$ & $<0.01$ & 1.1 & $0.6-2.3$ & 0.72 \\
\cline { 2 - 7 } & LAD distal & 2.6 & $1.3-5.4$ & $<0.01$ & 1.1 & $0.4-2.9$ & 0.83 \\
\cline { 2 - 7 } & LCX proximal & 1.9 & $0.9-3.8$ & 0.08 & 1.0 & $0.4-2.4$ & 0.96 \\
\cline { 2 - 7 } & LCX distal & 1.6 & $0.8-3.2$ & 0.18 & 1.2 & $0.6-2.5$ & 0.68 \\
\hline CTO-related artery & RCA & - & - & - & - & 0.4 & $0.7-2.9$ \\
\cline { 2 - 8 } & LAD proximal & 1.2 & $0.7-2.0$ & 0.51 & 1.4 & 0.33 \\
\cline { 2 - 8 } & LAD distal & 0.2 & $0.05-0.8$ & 0.03 & 0.4 & 0.19 \\
\cline { 2 - 8 } & LCX proximal & 0.6 & $0.3-1.4$ & 0.25 & 0.6 & $0.2-1.4$ & 0.20 \\
\cline { 2 - 8 } & LCX distal & 0.8 & $0.5-1.4$ & 0.48 & 1.0 & $0.5-1.8$ & 0.94 \\
\hline
\end{tabular}

Multivariate analysis: corrected for age, gender, statin use and cardiogenic shock. Cl: confidence interval; CTO: chronic total occlusion; HR: hazard ratio; LAD: left anterior descending artery; LCX: left circumflex coronary artery; RCA: right coronary artery; STEMI: ST-elevation myocardial infarction 
left ventricular ejection fraction (LVEF), caused by a larger final infarct size $\mathrm{e}^{19,21-26}$. In addition, the observed lower myocardial blush grade $(\mathrm{MBG})$ in proximal LAD culprit lesions could be related to a larger infarct size, more oedema, higher filling pressures, and increased downstream microvascular resistance ${ }^{27}$. Comparable findings have been observed in STEMI patients with a CTO in whom mortality, residual left ventricular function, haemodynamic stability, ST-segment resolution and MBG were worse compared to non-CTO STEMI patients ${ }^{15-17,27,28}$; however, these endpoints have never been specified according to coronary location.

Another explanatory mechanism could be an alteration in the balance of the autonomic nervous system owing to the location of coronary occlusion, which has been associated with life-threatening ventricular arrhythmias and cardiac death in survivors of myocardial infarction $^{29}$. Sympathetic innervation is less pronounced in the inferior compared with the anterior myocardial wall, whereas vagal afferent receptors have a preferential distribution on the posterior wall of the left ventricle ${ }^{30,31}$. In animal experiments, vagal stimulation or sympathetic inhibition reduces the threshold for ventricular fibrillation ${ }^{32}$. Therefore, patients with an acute inferior occlusion after myocardial infarction might be relatively protected from ventricular fibrillation in contrast to patients with an acute anterior occlusion who might have a higher frequency of ventricular arrhythmia. In a small cohort $(\mathrm{n}=23)$, CTO PCI has proven to have a beneficial effect on the autonomic nervous system in the LAD artery, which was not observed after CTO PCI of the RCA ${ }^{33}$. These findings suggest a potential antiarrhythmic effect after LAD revascularisation, resulting from a shift in the autonomic balance in favour of the parasympathetic nervous system.

Our cohort presents a group with high mortality rates of between $15.1 \%$ and $38.5 \%$, depending on the combination of coronary location. In a large cohort of STEMI patients treated with primary PCI, the five-year mortality rates for single-vessel disease (SVD), multivessel disease (MVD) without CTO and MVD with CTO were $14 \%, 20 \%$ and $38 \%$, respectively ${ }^{15}$. Our data emphasise the need for further assessment of the optimal treatment strategy in these challenging patients.

At present, no randomised data exist as to whether revascularisation of a CTO in STEMI or stable angina patients can actually reverse the observed worse outcome. Currently, three randomised trials are enrolling patients, one in STEMI patients, the EXPLORE trial ${ }^{34}$, which will evaluate whether CTO PCI in a non-IRA within seven days of primary PCI can improve LVEF and reduce left ventricular end-diastolic volume at four-month follow-up, compared with optimal medical therapy in 300 STEMI patients. The other two randomised clinical trials are currently enrolling patients with CTO and stable coronary artery disease, namely the EuroCTO trial ${ }^{35}$, which will randomly assign 1,200 patients to receive either PCI with DES and optimal medical therapy or optimal medical therapy alone. The primary endpoint is quality of life at one year and major cardiovascular events at three years. Similarly, the DECISION-CTO trial $^{36}$ will randomly assign 1,284 patients to receive PCI with DES and optimal medical therapy or optimal medical therapy alone. The primary endpoint is a composite of all-cause mortality, myocardial infarction, stroke, and any revascularisation at three-year followup. Although randomised data are lacking, observational studies have shown several beneficial effects after CTO revascularisation in patients with stable angina, such as improvement in angina and quality of life $^{7}$, a potential improvement in electrical myocardial stability $^{9,10}$, a reduced need for CABG surgery ${ }^{8}$, enhanced tolerance of future coronary events, increased left ventricular function, and a substantial increase in survival ${ }^{11}$. Two observational studies evaluated the difference in survival after CTO revascularisation in patients with stable CAD according to the target vessel and found only a survival benefit after successful CTO PCI in either the LAD or the LCX artery, but not in the RCA ${ }^{12,13}$. As mentioned above, survival data in STEMI patients after CTO revascularisation are absent.

\section{Limitations}

Several limitations are applicable to this study. Importantly, our study was limited by its observational nature and its modest cohort size. Due to the unbalanced known IRA distribution in a general STEMI population, with the LCX being the least frequent IRA and the RCA being the most frequent CTO artery, there is an overall unbalanced distribution of combinations of (CTO/IRA) arteries. Although this is in accordance with daily clinical practice, it may be a limitation upon interpreting the presented results ${ }^{6}$. Furthermore, although multivariate Cox proportional hazards models were constructed, unknown or unmeasured confounders may still have introduced bias. No complete data were available on possible mechanisms explaining the observed difference in mortality by target vessel, such as infarct size and left ventricular function. More research is needed to elucidate these mechanisms. Last, the coronary angiograms were not analysed by an independent core lab.

\section{Conclusions}

In conclusion, we previously reported that STEMI patients with a CTO have a worse prognosis than STEMI patients without a CTO. We now show that in these patients LAD or proximal LCX location for the culprit lesion or proximal LAD location for the CTO lesion is associated with the highest risk. As a result, almost all CTO patients are at increased risk for mortality due to the combination of the culprit and CTO artery location.

\section{Impact on daily practice}

This report shows that the highest risk of mortality was observed when the culprit lesion was located in the LAD or proximal LCX or when the CTO lesion was located in the proximal LAD. In clinical practice, these patients constitute a very high risk group. Whether CTO intervention in addition to primary PCI could improve prognosis will be answered shortly in the EXPLORE trial. The patients who would theoretically benefit the most regarding mortality are those in whom the culprit lesion is located in the LAD or proximal LCX or those in whom the CTO lesion is located in the proximal LAD. 


\section{Conflict of interest statement}

The authors have no conflicts of interest to declare.

\section{References}

1. Burggraf GW, Parker JO. Prognosis in coronary artery disease. Angiographic, hemodynamic, and clinical factors. Circulation. 1975;51:146-56.

2. Friesinger GC, Page EE, Ross RS. Prognostic significance of coronary arteriography. Trans Assoc Am Physicians. 1970;83:78-92.

3. Reeves TJ, Oberman A, Jones WB, Sheffield LT. Natural history of angina pectoris. Am J Cardiol. 1974;33:423-30.

4. Ringqvist I, Fisher LD, Mock M, Davis KB, Wedel H, Chaitman BR, Passamani E, Russell RO Jr, Alderman EL, Kouchoukas NT, Kaiser GC, Ryan TJ, Killip T, Fray D. Prognostic value of angiographic indices of coronary artery disease from the Coronary Artery Surgery Study (CASS). J Clin Invest. 1983;71: 1854-66.

5. Fefer P, Knudtson ML, Cheema AN, Galbraith PD, Osherov AB, Yalonetsky S, Gannot S, Samuel M, Weisbrod M, Bierstone D, Sparkes JD, Wright GA, Strauss BH. Current perspectives on coronary chronic total occlusions: the Canadian Multicenter Chronic Total Occlusions Registry. J Am Coll Cardiol. 2012;59: 991-7.

6. Ramunddal T, Hoebers L, Henriques JP, Dworeck C, Angeras O, Odenstedt J, Ioanes D, Olivecrona G, Harnek J, Jensen U, Aasa M, Jussila R, James S, Lagerqvist B, Matejka G, Albertsson P, Omerovic E. Chronic total occlusions in Sweden--a report from the Swedish Coronary Angiography and Angioplasty Registry (SCAAR). PLoS One. 2014;9:e103850.

7. Grantham JA, Jones PG, Cannon L, Spertus JA. Quantifying the early health status benefits of successful chronic total occlusion recanalization: Results from the FlowCardia's Approach to Chronic Total Occlusion Recanalization (FACTOR) Trial. Circ Cardiovasc Qual Outcomes. 2010;3:284-90.

8. Khan MF, Wendel CS, Thai HM, Movahed MR. Effects of percutaneous revascularization of chronic total occlusions on clinical outcomes: a meta-analysis comparing successful versus failed percutaneous intervention for chronic total occlusion. Catheter Cardiovasc Interv. 2013;82:95-107.

9. Nombela-Franco L, Mitroi CD, Fernandez-Lozano I, GarciaTouchard A, Toquero J, Castro-Urda V, Fernandez-Diaz JA, PerezPereira E, Beltran-Correas P, Segovia J, Werner GS, Javier G, Luis AP. Ventricular arrhythmias among implantable cardioverterdefibrillator recipients for primary prevention: impact of chronic total coronary occlusion (VACTO Primary Study). Circ Arrhythm Electrophysiol. 2012;5:147-54.

10. Opitz CF, Finn PV, Pfeffer MA, Mitchell GF, Pfeffer JM. Effects of reperfusion on arrhythmias and death after coronary artery occlusion in the rat: increased electrical stability independent of myocardial salvage. J Am Coll Cardiol. 1998;32: 261-7.

11. Hoebers LP, Claessen BE, Elias J, Dangas GD, Mehran R, Henriques JP. Meta-analysis on the impact of percutaneous coronary intervention of chronic total occlusions on left ventricular function and clinical outcome. Int J Cardiol. 2015;187:90-6.

12. Claessen BE, Dangas GD, Godino C, Henriques JP, Leon MB, Park SJ, Stone GW, Moses JW, Colombo A, Mehran R; Multinational CTO Registry. Impact of target vessel on long-term survival after percutaneous coronary intervention for chronic total occlusions. Catheter Cardiovasc Interv. 2013;82:76-82.

13. Safley DM, House JA, Marso SP, Grantham JA, Rutherford BD. Improvement in survival following successful percutaneous coronary intervention of coronary chronic total occlusions: variability by target vessel. JACC Cardiovasc Interv. 2008; 1 : 295-302.

14. Bataille Y, Déry JP, Larose E, Déry U, Costerousse O, RodésCabau J, Rinfret S, De Larochellière R, Abdelaal E, MacHaalany J, Barbeau G, Roy L, Bertrand OF. Prevalence, predictors and clinical impact of unique and multiple chronic total occlusion in noninfarct-related artery in patients presenting with ST-elevation myocardial infarction. Heart. 2012;98:1732-7.

15. Claessen BE, van der Schaaf RJ, Verouden NJ, Stegenga NK, Engstrom AE, Sjauw KD, Kikkert WJ, Vis MM, Baan J Jr, Koch KT, de Winter RJ, Tijssen JG, Piek JJ, Henriques JP. Evaluation of the effect of a concurrent chronic total occlusion on long-term mortality and left ventricular function in patients after primary percutaneous coronary intervention. JACC Cardiovasc Interv. 2009;2: 1128-34.

16. Claessen BE, Dangas GD, Weisz G, Witzenbichler B, Guagliumi G, Möckel M, Brener SJ, Xu K, Henriques JP, Mehran R, Stone GW. Prognostic impact of a chronic total occlusion in a noninfarct-related artery in patients with ST-segment elevation myocardial infarction: 3-year results from the HORIZONS-AMI trial. Eur Heart J. 2012;33:768-75.

17. Lexis CP, van der Horst IC, Rahel BM, Lexis MA, Kampinga MA, Gu YL, de Smet BJ, Zijlstra F. Impact of chronic total occlusions on markers of reperfusion, infarct size, and longterm mortality: a substudy from the TAPAS-trial. Catheter Cardiovasc Interv. 2011;77:484-91.

18. Elhendy A, Mahoney DW, Khandheria BK, Paterick TE, Burger KN, Pellikka PA. Prognostic significance of the location of wall motion abnormalities during exercise echocardiography. $J$ Am Coll Cardiol. 2002;40:1623-9.

19. Elsman P, van 't Hof AW, Hoorntje JC, de Boer MJ, Borm GF, Suryapranata H, Ottervanger JP, Gosselink AT, Dambrink JH, Zijlstra F. Effect of coronary occlusion site on angiographic and clinical outcome in acute myocardial infarction patients treated with early coronary intervention. Am J Cardiol. 2006;97:1137-41.

20. Henriques JP, Zijlstra F, van 't Hof AW, de Boer MJ, Dambrink JH, Gosselink AT, Hoorntje JC, Ottervanger JP, Suryapranata H. Primary percutaneous coronary intervention versus thrombolytic treatment: long term follow up according to infarct location. Heart. 2006;92:75-9.

21. St John Sutton M, Pfeffer MA, Plappert T, Rouleau JL, Moye LA, Dagenais GR, Lamas GA, Klein M, Sussex B, Goldman S, et al. Quantitative two-dimensional echocardiographic 
measurements are major predictors of adverse cardiovascular events after acute myocardial infarction. The protective effects of captopril. Circulation. 1994;89:68-75.

22. Arsanjani R, Berman DS, Gransar H, Cheng VY, Dunning A, Lin FY, Achenbach S, Al-Mallah M, Budoff MJ, Callister TQ, Chang HJ, Cademartiri F, Chinnaiyan KM, Chow BJ, DeLago A, Hadamitzky M, Hausleiter J, Kaufmann P, LaBounty TM, Leipsic J, Raff G, Shaw LJ, Villines TC, Cury RC, Feuchtner G, Kim YJ, Min JK; CONFIRM Investigators. Left ventricular function and volume with coronary CT angiography improves risk stratification and identification of patients at risk for incident mortality: results from 7758 patients in the prospective multinational CONFIRM observational cohort study. Radiology. 2014;273:70-7.

23. De Silva K, Webb I, Sicard P, Lockie T, Pattinson S, Redwood S, Perera D. Does left ventricular function continue to influence mortality following contemporary percutaneous coronary intervention? Coron Artery Dis. 2012;23:155-61.

24. Norris RM, White HD. Therapeutic trials in coronary thrombosis should measure left ventricular function as primary end-point of treatment. Lancet. 1988;1:104-6.

25. Petriz JL, Gomes BF, Rua BS, Azevedo CF, Hadlich MS, Mussi HT, Taets Gde C, Nascimento EM, Pereira Bde B, Silva NA. Assessment of myocardial infarction by cardiac magnetic resonance imaging and long-term mortality. Arq Bras Cardiol. 2015;104:159-68..

26. Roes SD, Kelle S, Kaandorp TA, Kokocinski T, Poldermans D, Lamb HJ, Boersma E, van der Wall EE, Fleck E, de Roos A, Nagel E, Bax JJ. Comparison of myocardial infarct size assessed with contrast-enhanced magnetic resonance imaging and left ventricular function and volumes to predict mortality in patients with healed myocardial infarction. Am J Cardiol. 2007;100:930-6.

27. Atmaca Y, Duzen V, Ozdol C, Altin T, Tulunay C, Ertas F, Erol C. Total blush score: a new index for the assessment of microvascular perfusion in idiopathic dilated cardiomyopathy. Coron Artery Dis. 2008;19:181-5.

28. Hoebers LP, Vis MM, Claessen BE, van der Schaaf RJ, Kikkert WJ, Baan J Jr, de Winter RJ, Piek JJ, Tijssen JG, Dangas GD, Henriques JP. The impact of multivessel disease with and without a co-existing chronic total occlusion on short- and long-term mortality in ST-elevation myocardial infarction patients with and without cardiogenic shock. Eur J Heart Fail. 2013;15:425-32.

29. La Rovere MT, Bigger JT Jr, Marcus FI, Mortara A, Schwartz PJ. Baroreflex sensitivity and heart-rate variability in prediction of total cardiac mortality after myocardial infarction. ATRAMI (Autonomic Tone and Reflexes After Myocardial Infarction) Investigators. Lancet. 1998;351:478-84.

30. Airaksinen KE. Autonomic mechanisms and sudden death after abrupt coronary occlusion. Ann Med. 1999;31:240-5.

31. Webb SW, Adgey AA, Pantridge JF. Autonomic disturbance at onset of acute myocardial infarction. Br Med J. 1972;3:89-92.

32. Schwartz PJ, Stone HL. Left stellectomy in the prevention of ventricular fibrillation caused by acute myocardial ischemia in conscious dogs with anterior myocardial infarction. Circulation. 1980;62:1256-65.

33. Szwoch M, Ambroch-Dorniak K, Sominka D, Dorniak W, Danilowicz-Szymanowicz L, Krassowski W, Raczak G. Comparison the effects of recanalisation of chronic total occlusion of the right and left coronary arteries on the autonomic nervous system function. Kardiol Pol. 2009;67:467-74.

34. van der Schaaf RJ, Claessen BE, Hoebers LP, Verouden NJ, Koolen JJ, Suttorp MJ, Barbato E, Bax M, Strauss BH, Olivecrona GK, Tuseth V, Glogar D, Ramunddal T, Tijssen JG, Piek JJ, Henriques JP; EXPLORE investigators. Rationale and design of EXPLORE: a randomized, prospective, multicenter trial investigating the impact of recanalization of a chronic total occlusion on left ventricular function in patients after primary percutaneous coronary intervention for acute ST-elevation myocardial infarction. Trials. 2010;11:89.

35. A Randomized Multicentre Trial to Evaluate the Utilization of Revascularization or Optimal Medical Therapy for the Treatment of Chronic Total Coronary Occlusions (EuroCTO). http://clinicaltrials.gov/ct2/show/NCT01760083?term=EUROCTO\&rank=1. 2013.

36. Drug-Eluting Stent Implantation Versus Optimal Medical Treatment in Patients With Chronic Total Occlusion (DECISIONCTO). NCT01078051. http://clinicaltrials.gov/ct2/show/NCT010 78051?term=DECISION-CTO\&rank=1. 2013. 